\title{
CONHECIMENTO DOS PROFISSIONAIS DE ENFERMAGEM SOBRE O CUIDADO HUMANIZADO EM UMA UNIDADE DE TERAPIA INTENSIVA NEONATAL
}

\author{
NURSING PROFESSIONALS' KNOWLEDGE OF HUMANIZED \\ CARE IN A NEONATAL INTENSIVE CARE UNIT
}

\section{Maria Fernanda Pereira Gomes ${ }^{a}$, Natália Santos da Silvab, Verusca Kelly Capellinic, Mariana Souza Santos ${ }^{d}$}

\begin{abstract}
amferpg@usp.br, bnataliasantosdasilva887@gmail.com, 'cveruscakelly@hotmail.com, ${ }^{\mathrm{d}}$ marisouzastos@hotmail.com.
\end{abstract} Universidade Paulista - Assis (SP), Brasil.

Data de recebimento do artigo: 02/01/2017 Data de aceite do artigo: 19/04/2017

\section{RESUMO}

Objetivo: Identificar o conhecimento dos profissionais de enfermagem que trabalham em uma unidade de terapia intensiva neonatal (Utin) sobre o cuidado humanizado ao recém-nascido. Método: Estudo quantitativo e descritivo, realizado em uma Utin de um hospital do interior do estado de São Paulo, Brasil. Os sujeitos do estudo foram 24 profissionais de enfermagem, dentre os quais seis enfermeiros, cinco técnicos e 13 auxiliares. Os dados foram coletados por meio de um questionário elaborado a partir do referencial teórico do Ministério da Saúde sobre humanização. Resultados: Por unanimidade, os profissionais de enfermagem consideram como cuidado humanizado a utilização de técnicas que amenizem a dor durante a realização de procedimentos dolorosos. Outras características apontadas por grande parte dos profissionais entrevistados foram higienizar e aquecer as mãos quando for tocar no bebê e minimizar os sons e ruídos para melhorar seu conforto. As características menos apontadas foram: permitir que todos os familiares toquem no bebê e a resolutividade. Conclusáo: Os profissionais de enfermagem percebem o cuidado humanizado como prática importante a ser realizada todos os dias tanto com os recém-nascidos quanto com as famílias. No entanto, poucos responderam conhecer as competências e atribuiçóes que devem ter em relaçáo ao cuidado do recém-nascido e o nível de resolutividade que faz parte do cuidado humanizado.

Palavras-chave: Humanização da assistência; unidades de terapia intensiva neonatal; cuidados de enfermagem.

\section{ABSTRACT}

Objective: To identify the knowledge of nursing professionals working in a neonatal intensive care unit (Nicu) of the humanized care for newborns. Method: This is a quantitative and descriptive study, carried out in a Nicu of a hospital in the state of São Paulo, Brazil. The study subjects were 24 nursing professionals, including 6 nurses, 5 nurse technicians and 13 assistants. Data were collected through a questionnaire prepared from the theoretical framework of the Ministry of Health on Humanization. Results: Unanimously nursing professionals regard as humanized care the use of techniques that mitigate pain when performing painful procedures. Other characteristics indicated by most of the professionals interviewed were to sanitize and warm their hands when touching the baby and to minimize sounds and noises to improve comfort. Yet, the less identified characteristics were allowing all family members to touch the baby and resoluteness. Conclusion: The nurses understand humanized care as an important practice to be held every day with the newborn and his or her family, however, few answered that they know about the powers and duties that they should have regarding the newborn care and the level of resoluteness that is an important part of humanized care.

Keywords: Humanization of assistance; intensive care units, neonatal; nursing care. 


\section{Introdução}

O Programa de Humanização no Pré-natal e Nascimento, instituído pelo Ministério da Saúde por meio da Portaria GM/MS no 569, de 1 de junho de 2000, estabelece que todo recém-nascido tem direito à assistência neonatal de forma humanizada e segura, com a adoção de medidas e procedimentos benéficos, evitando práticas intervencionistas desnecessárias ${ }^{1}$.

O avanço tecnológico na área da saúde trouxe grandes benefícios para o tratamento e a recuperação de recém-nascidos prematuros de alto risco, aumentando as chances de sobrevivência de muitos neonatos. No entanto, a incorporação da tecnologia nem sempre veio acompanhada de humanização.

Nessa perspectiva, os cuidados dispensados aos recém-nascidos devem estar atrelados à integralidade e à humanização, buscando garantir assistência à saúde resolutiva e de qualidade ${ }^{2}$. Para tanto, o cuidado humanizado visa conciliar a melhor tecnologia disponível com a promoção do acolhimento e atendimento resolutivo aos recém-nascidos e seus familiares ${ }^{3}$. Para que ocorra a incorporação do cuidado humanizado nas práticas diárias da equipe de enfermagem, é necessário ter ciência a respeito do conhecimento da equipe sobre o tema da humanizaçáo, realizando diagnóstico local do processo de trabalho.

Com vistas ao desenvolvimento do conhecimento da equipe de saúde, faz-se necessária uma reflexão sobre as ações realizadas no cotidiano e maior preparo dos profissionais, não só sob os aspectos teórico e técnico, mas também voltado à transformação da assistência em uma perspectiva mais humanitária ${ }^{4}$. Esta pesquisa justifica-se pela importância de apontar o conhecimento dos profissionais de enfermagem sobre cuidado humanizado, assunto vinculado à qualidade de vida dos recém-nascidos, familiares e profissionais da saúde, para que seja dada ênfase à aplicaçáo desse tema no cotidiano das práticas de saúde e para valorizar o exercício do cuidado humanizado na unidade de terapia intensiva neonatal (Utin).

No intuito de entender a concepçáo de cuidado humanizado por parte dos profissionais de enfermagem, o objetivo deste estudo foi identificar e analisar, em uma Utin de um hospital regional do interior do estado de São Paulo, o conhecimento desses profissionais sobre esse tipo de acolhida.

\section{Método}

Trata-se de um estudo quantitativo, descritivo e exploratório. A amostra foi constituída pelo universo de profissionais de enfermagem - enfermeiros, auxiliares e técnicos de enfermagem - que trabalhavam na Utin de um hospital no município de Assis, interior do estado de São Paulo, Brasil, no período de julho de 2014. Do total de 42 profissionais de enfermagem, 24 aceitaram participar da pesquisa, sendo seis enfermeiros, cinco técnicos de enfermagem e 13 auxiliares de enfermagem.

O questionário utilizado para coleta de dados, elaborado pelos próprios autores a partir do referencial teórico do Ministério da Saúde², foi constituído das seguintes questóes:

1. Para você, é importante que os pais do recém-nascido saibam e participem das decisóes sobre o tratamento na UTI neonatal? (Com as opçóes de resposta: "sim", "em algumas situações", "talvez", "não sei" e "não").

2. Para você, o cuidado humanizado ao recém-nascido deve ser uma prática? (Com as opçôes de resposta: "diária", "presente", "esporádica" e "nunca realizada").

3. Para você, é importante, nos momentos de realização de procedimentos dolorosos, utilizar técnicas que amenizem a dor do recém-nascido? (Com as respostas: "sim", "em algumas situaçôes", "talvez", "não sei" e "não").

4. Para você, quais as características de um cuidado humanizado? (Pode assinalar mais de uma resposta). (Com as opçóes de resposta: "resolutividade", "boas práticas de enfermagem", "conversar com o bebê enquanto realiza os cuidados", "higienizar e aquecer as máos quando for tocar o bebê", "minimizar os sons e ruídos para melhor conforto", "facilitar o contato da mãe e família com o recém-nascido precocemente", "deixar que todos os familiares toquem no bebê para permitir contato e a humanização", "incentivar o aleitamento materno, quando indicado", "saber as competências e atribuiçôes que devem ser desempenhadas em relação ao recém-nascido").

5. Você já recebeu capacitação profissional sobre o assunto humanização? (Com as opções de resposta: "sim, muitas vezes (mais de três vezes)"; "sim, algumas vezes (mais de duas vezes)"; "sim, uma vez"; "não lembro"; "nunca").

Os questionários foram preenchidos pelos profissionais de enfermagem que aceitaram participar da pesquisa. Os dados foram digitados em uma planilha formatada no Microsoft Excel (versão 2007) e submetidos à análise de consistência mediante a dupla digitação. Após comparação das duas planilhas digitadas e correção das divergências, os dados foram organizados e analisados. As respostas dos participantes possibilitaram a elaboração de indicadores de cuidado de enfermagem humanizado conforme mostra a Tabela 1 .

Esta pesquisa foi aprovada pelo Comitê de Ética em Pesquisa sob o parecer no 994.302. A pesquisa também foi aprovada pelo gestor de saúde do hospital envolvido. 


\section{Resultados}

Neste estudo os profissionais entrevistados julgam ser importante o conhecimento dos pais sobre o diagnóstico, o tratamento e o prognóstico dos recém-nascidos, e admitem a importância destes nas decisóes sobre o tratamento dos filhos. Outro dado relevante é que os profissionais afirmam que o cuidado humanizado deve ser sempre aplicado ao recém-nascido em Utin, e julgam importantes técnicas que amenizem a dor durante a realização de procedimentos dolorosos. Os dados relativos às características do cuidado humanizado estão expressos na Tabela 1.

Quando os profissionais foram questionados sobre sua participação em cursos ou eventos científicos específicos sobre a humanização do cuidado, 29,2\% deles afirmaram que, nos últimos anos, participaram de capacitaçôes profissionais sobre humanização mais de três vezes; $25,0 \%$ algumas vezes; $29,2 \%$ participaram apenas uma vez; e 16,6\% afirmaram não se lembrar ou que nunca participaram.

Tabela 1: Conhecimento dos profissionais de saúde sobre as características de um cuidado humanizado.

\begin{tabular}{|c|c|c|}
\hline Indicadores & $\mathbf{N}$ & $\%$ \\
\hline Resolutividade & 10 & 41,7 \\
\hline Boas práticas de enfermagem & 19 & 79,2 \\
\hline Participação dos pais nas decisões sobre o tratamento & 16 & 66,7 \\
\hline Conversar com o bebê enquanto realiza os cuidados & 21 & 87,5 \\
\hline Higienizar e aquecer as mãos quando for tocar no bebê & 22 & 91,7 \\
\hline $\begin{array}{l}\text { Importância de se utilizar técnicas que amenizem a dor } \\
\text { durante a realizaçáo de procedimentos dolorosos }\end{array}$ & 24 & 100 \\
\hline Minimizar os sons e ruídos para melhorar conforto & 22 & 91,7 \\
\hline $\begin{array}{l}\text { Facilitar o contato da mãe e família } \\
\text { com o recém-nascido precocemente }\end{array}$ & 19 & 79,2 \\
\hline $\begin{array}{l}\text { Deixar que todos os familiares toquem o } \\
\text { bebê para permitir contato e a humanização }\end{array}$ & 2 & 8,3 \\
\hline Incentivo ao aleitamento materno & 19 & 79,2 \\
\hline $\begin{array}{l}\text { Saber as competências e atribuiçóes que devem ser } \\
\text { desempenhadas em relaçấo ao recém-nascido }\end{array}$ & 16 & 66,7 \\
\hline
\end{tabular}

Fonte: Elaborado pelos autores a partir dos dados coletados, 2015.

\section{Discussão}

Nesta pesquisa, identificou-se que os profissionais de enfermagem sabem o que é o cuidado humanizado e tentam colocá-lo em prática diariamente. No entanto, observa-se que mais da metade dos profissionais não considera a resolutividade como parte de um cuidado humanizado. Outros dois aspectos menos assinalados como importantes para os profissionais foram a "participaçáo dos pais nas decisóes sobre o tratamento" e "saber as competências e atribuições que devem ser desempenhadas em relação ao recém-nascido". Observa-se que embora parte dos profissionais entrevistados defenda o conhecimento dos pais sobre o diagnóstico, tratamento e prognóstico do recém-nascido, nem todos julgaram importante a autonomia destes no tratamento dos filhos, em que a família é consultada somente em situações extremas ${ }^{5,6}$. Essas informaçóes confirmam os resultados de um estudo de revisão bibliográfica no qual se afirmava que os pais de recém-nascidos internados têm muita dificuldade na autonomia do tratamento de seus filhos, por falta de informação ou esclarecimento 5 .

É importante que os profissionais que atuam na Utin estejam aptos para amenizar o dano emocional causado aos familiares pela internação da criança, por meio de uma assistência humanizada prestada não só a ela, mas também aos pais, agindo de forma integral, tentando interagir com os familiares, atendendo a necessidades, apoiando, ensinando e incentivando a participação destes no cuidado ${ }^{7,8}$.

Nessa perspectiva, humanizar a assistência à família e ao bebê implica em oferecer um cuidado integral e singular a ambos, dando ênfase às suas crenças, valores, individualidades e personalidades, uma vez que cada ser é único, embora envolvido em um contexto familiar que possui uma história de vida e, por isso, deve ser respeitado para que seja mantida a dignidade desse grupo durante a hospitalização?.

Assim, é oportuno repensar as açóes em saúde nesse âmbito, tendo em vista a humanização da assistência em Utins pautada no atendimento às necessidades de todos os agentes envolvidos nesse processo?.

Dentre as características do cuidado humanizado, a mais assinalada foi a higienização das mãos ao tocar o recém-nascido. A higienização das mãos é a maneira mais simples e eficiente de prevenir possíveis infecçôes neonatais ${ }^{10}$. Outras características do cuidado humanizado assinaladas pela maioria dos profissionais foram: a minimizaçáo dos sons e ruídos para o conforto do recém-nascido e conversar com o bebê enquanto realiza os cuidados de enfermagem. Muitas pesquisas apontam a preocupação das equipes de enfermagem em minimizar os ruídos que provocam alteraçóes fisiológicas e comportamentais no recém-nascido, buscando minimizar esses sons para o conforto do bebêt $\hat{e}^{3,5,6,11}$.

Com base nos resultados, percebe-se a preocupação do profissional de enfermagem com o risco de infecção ao recém-nascido, destacando como primeira característica do cuidado humanizado a higienização das mãos e o impedimento do contato de outros familiares com o recém-nascido de risco.

Por unanimidade, os profissionais que participaram desta pesquisa consideraram que utilizar técnicas que amenizam a dor durante a realização de procedimentos dolorosos no recém-nascido faz parte do cuidado humanizado. A utilização dessas técnicas, conforme consta 
no item 7 da Resolução no 41, de 13 de outubro de 1995, do Conselho Nacional dos Direitos da Criança e do Adolescente (Conanda), acerca dos direitos da criança e do adolescente hospitalizados, é um "direito náo sentir dor, quando existem meios para evitá-la” ${ }^{12}$. Nesta e em outras pesquisas, os profissionais de enfermagem defendem as práticas que amenizam a dor neonatal ${ }^{1,13}$.

A equipe de enfermagem pode e deve utilizar medidas não farmacológicas de forma constante para o controle da dor nas unidades neonatais, já que são estratégias de cuidado que não necessitam da interferência de outros profissionais. Medidas de conforto e de controle da dor, como o toque, o contato pele a pele, a nutrição não nutritiva, dentre outras, podem ser realizadas sistematicamente com vistas a prevenir a dor, limitá-la e restabelecer o bem-estar do recém-nascido ${ }^{14}$.

$\mathrm{O}$ aleitamento materno também foi apontado como cuidado humanizado, pois promove melhor desenvolvimento do recém-nascido ${ }^{11,13}$. O vínculo da mãe e da família com o bebê também foi destacado como uma importante ferramenta no cuidado; em outras pesquisas, a formação desse vínculo é dada na inclusão dos pais na atenção e com o Método Canguru 3,15.

Para promover e apoiar a amamentaçáo na Utin, além do conhecimento em aleitamento materno e competência clínica, o profissional de saúde precisa possuir habilidade para se comunicar com a nutriz, sendo necessário abordar os princípios básicos que implicam em acolher, ajudar a mulher a tomar decisôes de forma empática, saber ouvir, apreender, desenvolver a confiança e dar apoio. No caso da equipe de enfermagem, seu papel é o de informar as famílias sobre os benefícios do leite materno, fornecer suporte e cuidado à mulher nutriz e seu filho, propor intervençóes para obter uma lactação efetiva e fortalecer o vínculo familiar ${ }^{16}$.

Em relação a permitir que outros familiares toquem o recém-nascido, a maioria dos entrevistados acredita que tal ação não faz parte do cuidado humanizado, assim como em outras Utins pesquisadas, devido ao risco de infecção ${ }^{11}$. Entretanto, outras pesquisas indicam esse aspecto como uma intervenção a ser implantada ${ }^{3,5}$.

Dentre os fatores que dificultam a humanização na Utin e podem interferir na atenção e orientação aos pais e no tratamento adequado ao recém-nascido, destacam-se a ambiência local que, pela incorporação tecnológica, torna-se um ambiente frio e hostil aos familiares; a falta de sensibilidade e mecanização do processo de trabalho dos profissionais; as jornadas longas de trabalho; e os desgastes físicos e emocionais dos profissionais.

Apesar do grande esforço que os profissionais de enfermagem possam realizar no sentido de humanizar o cuidado em Utin, essa é uma tarefa difícil, pois deman$\mathrm{da}$ atitudes às vezes individuais contra todo um sistema tecnológico dominante. E, em certas ocasiōes, a própria dinâmica do trabalho desses profissionais em uma UTI não possibilita momentos de reflexão acerca de seu processo de trabalho, ${ }^{9,17}$.

A presença efetiva da equipe de enfermagem com escuta sensível é tấo importante quanto o procedimento técnico, uma vez que nem sempre os conhecimentos técnicos funcionam tão bem diante das situaçôes de estresse. Somente vendo, escutando e sentindo o recém-nascido e a família como um todo é que se pode atender e compreender a essência do cuidar humano?.

Quando questionados sobre a atualização profissional em humanização, as respostas dos entrevistados ficaram divididas entre "sim" e "não". O conhecimento científico e as habilidades técnicas são de extrema importância na reduçáo da mortalidade infantil dos recém-nascidos de risco, bem como a humanização dos cuidados dispensados ao neonato; destaca-se, assim, a importância da capacitação do profissional de enfermagem nos avanços tecnológicos e terapêuticos dessa área ${ }^{5,18}$.

Para melhorar a prática do cuidado humanizado na Utin, a equipe de enfermagem deve ser capacitada e saber executar os cuidados humanizados com os recém-nascidos internados, além de fortalecer o vínculo do recém-nascido com sua família, liberando a visita de outros integrantes da família e a preparação destes quanto ao aspecto da criança, sobre os equipamentos conectados a ela e o ambiente da Utin. A oportunidade de tocar e visualizar o recém-nascido é importante para o apego e vínculo da mãe com o bebê. Além disso, é fundamental incentivar os pais a participar dos cuidados com o bebê e conhecer o quadro clínico do recém-nascido, estreitando, também, as relaçóes entre os pais e a equipe de enfermagem.

\section{Conclusão}

Os profissionais de enfermagem que participaram desta pesquisa percebem o cuidado humanizado como prática importante a ser realizada todos os dias com os recém-nascidos e sua família. Dentre as características do cuidado humanizado, esses profissionais elencam como mais importantes a utilização de técnicas que amenizem a dor durante a realização de procedimentos dolorosos, higienizaçáo e aquecimento das mãos para tocar no bebê, minimizaçáa dos sons e ruídos para melhorar o conforto do recém-nascido e conversar com o bebê enquanto realiza os cuidados.

Embora a maioria dos profissionais de enfermagem tenha demonstrado conhecer o que é o cuidado humanizado, pensando em boas práticas de enfermagem, poucos afirmaram que saber sobre as competências e atribuiçóes que devem ter em relação ao cuidado do 
recém-nascido faça parte da humanização dos cuidados. Outro ponto para refletir é que a maioria acredita que ser resolutivo não faz parte do cuidado humanizado. A capacitação dos profissionais de enfermagem, de acordo com o Programa de Humanização no Pré-natal e Nascimento, pode ser uma saída para melhorar o conhecimento destes profissionais e para a incorporação e aprimoramento do cuidado humanizado no processo de trabalho na Utin.

Para finalizar, faz-se necessária a realização de novas pesquisas que abordem o cuidado humanizado na Utin, para trazer visibilidade ao tema da humanização, prática imprescindível para a prestação de cuidados de enfermagem de qualidade aos recém-nascidos fragilizados e internados.

\section{Referências}

1. Brasil. Ministério da Saúde. Programa Humanização do Parto: humanização no pré-natal e nascimento. Brasília, DF: Ministério da Saúde; 2002.

2. Brasil. Ministério da Saúde. Humanização do parto e do nascimento. Brasília, DF: Ministério da Saúde; 2014.

3. Sá Neto JA, Rodrigues BMRD. Tecnologia como fundamento do cuidar em Neonatologia. Texto Contexto Enferm. 2010;19(2):372-77.

4. Caetano JA, Soares E, Andrade LM, Ponte RM. Cuidado humanizado em terapia intensiva: um estudo reflexivo. Esc Anna Nery R Enferm. 2007;11(2):325-30.

5. Martins CF, Fialho FA, Dias IV, Amaral JAM, Freitas SC. Unidade de terapia intensiva neonatal: o papel da enfermagem na construção de um ambiente terapêutico. R Enferm Cent O Min. 2011;1(2):268-76.

6. Cruvinel FG, Pauletti CM. Formas de atendimento humanizado ao recém-nascido pré-termo ou de baixo peso na unidade de terapia intensiva neonatal: uma revisão. Cad Pós-Grad Distúrb Desenvolv. 2009;9(1):102-25.

7. Centa ML, Moreira EC, Pinto MNGHR. A experiência vivida pelas famílias de crianças hospitalizadas em uma unidade de terapia intensiva neonatal. Texto Contexto Enferm. 2004;13(3):444-51.

8. Rocha DKL, Ferreira HC. Estado da arte sobre o cuidar em neonatologia: compromisso da enfermagem com a humanização na unidade de terapia intensiva neonatal. Enferm Foco (Brasília). 2013;4(1):24-8.

9. Reichert APS, Lins RNP, Collet N. Humanização do cuidado da UTI neonatal. Rev Eletr Enf [Internet]. 2007 [citado em 2014 jun 17];9(1):200-13. Disponível em: https://goo. gl/6Rndbe

10. Vancini A, Luz IP, Fonseca IAC, Barros MMA. Higienizaçáo das mãos na unidade de terapia intensiva neonatal. Rev Intertexto. 2014;1:1-14.

11. Weich TM, Ourique AC, Tochetto TM, Franceschi CM. Eficácia de um programa para redução de ruído em unidade de terapia intensiva neonatal. Rev Bras Ter Intensiva. 2011; 23(3):327-34.

12. Conselho Nacional dos Direitos da Criança e do Adolescente. Resoluçáo Conanda no 41, de 13 de outubro de 1995. Aprova em sua íntegra o texto oriundo da Sociedade Brasileira de Pediatria, relativo aos Direitos da Criança e do Adolescente Hospitalizados. Diário Oficial da União. Brasília, DF; 17 out 1995. Seção 1, p. 16319-20.

13. Brasil. Ministério da Saúde. Portaria GM no 930, de 10 de maio de 2012. Define as diretrizes e objetivos para a organização da atenção integral e humanizada ao recém-nascido grave ou potencialmente grave e os critérios de classificação e habilitação de leitos de Unidade Neonatal no âmbito do Sistema Único de Saúde (SUS). Diário Oficial da União. Brasília, DF; 11 maio 2012. Seção 1, p. 138-40.

14. Santos LM, Ribeiro IS, Santana RCB. Identificação e tratamento da dor no recém-nascido prematuro na Unidade de Terapia Intensiva. Rev Bras Enferm. 2012;65(2):269-75.

15. Brasil. Ministério da Saúde. Núcleo Técnico da Política Nacional de Humanização. HumanizaSUS: Política Nacional de Humanização. Brasília, DF: Ministério da Saúde; 2004.

16. Baptista SS, Alves VH, Souza RMP, Rodrigues DP, Cruz AFN, Branco MBLR. Manejo clínico da amamentação: atuaçáo do enfermeiro na unidade de terapia intensiva neonatal. Rev Enferm UFSM. 2015;5(1):23-31.

17. Oliveira B, Riegel F, Siqueira DS, Predebon CM. Humanização da assistência de enfermagem em unidade de terapia intensiva neonatal. Rev Enferm UFPI. 2014;3(2):98-102.

18. Rocha MCP, Carvalho MSM, Fossa AM, Rossato LM. Assistência humanizada na terapia intensiva neonatal: açóes e limitaçốes do enfermeiro. Saúde Rev. 2015;15(40):67-84.

Como citar este artigo:

Gomes MFP, Silva NS, Capellini VK, Santos MS. Conhecimento dos profissionais de enfermagem sobre o cuidado humanizado em uma unidade de terapia intensiva neonatal. Rev. Aten. Saúde. 2017;15(52):38-42. 